Supporting Information for

\title{
One Dense and Two Open Chiral Metal-organic Frameworks: Crystal Structures and Physical Properties
}

Shuangquan Zang, Yang Su, Yizhi Li, Zhuhui Zhen, Qingjin Meng*

Coordination Chemistry Institute, State Key Laboratory of Coordination Chemistry,

Nanjing University, Nanjing 210093, China; E-mail: Mengqj@nju.edu.cn 
Table S1. Geometry Parameters for Hydrogen Bonds in 2.

$\begin{array}{lccccc}\text { D-H } & \mathrm{d}(\mathrm{D}-\mathrm{H}) & \mathrm{d}(\mathrm{H} \cdots \mathrm{A}) & <\text { DHA } & \mathrm{d}(\mathrm{D} \cdots \mathrm{A}) & \mathrm{A} \\ \mathrm{O}(6)-\mathrm{H}(6 \mathrm{~B}) & 0.85 & 2.36 & 113.0 & 2.807(6) & \mathrm{O}(4)^{a} \\ \mathrm{O}(7)-\mathrm{H}(7 \mathrm{~A}) & 0.85 & 1.96 & 162.5 & 2.782(6) & \mathrm{O}(2)^{a} \\ \mathrm{O}(6)-\mathrm{H}(6 \mathrm{~A}) & 0.82 & 1.94 & 155.2 & 2.707(5) & \mathrm{O}(7) \\ \mathrm{O}(7)-\mathrm{H}(7 \mathrm{C}) & 0.85 & 2.00 & 149.3 & 2.765(6) & \mathrm{O}(10) \\ \mathrm{O}(8)-\mathrm{H}(8 \mathrm{~B}) & 0.85 & 2.43 & 121.4 & 2.964(5) & \mathrm{O}(2) \\ \mathrm{O}(11)-\mathrm{H}(11 \mathrm{D}) & 0.85 & 1.70 & 177.0 & 2.544(12) & \mathrm{O}(9)^{b} \\ \mathrm{O}(11)-\mathrm{H}(11 \mathrm{~B}) & 0.85 & 1.63 & 156.2 & 2.432(14) & \mathrm{O}(11)^{c}\end{array}$

Symmetry codes: ${ }^{a} \mathrm{x}, \mathrm{y}-1, \mathrm{z} ;{ }^{b} \mathrm{x}, \mathrm{y}, \mathrm{z}-1 ;{ }^{c}-\mathrm{x}+1, \mathrm{y},-\mathrm{z}$.

Table S2. Geometry Parameters for Hydrogen Bonds in 3.

$\begin{array}{llllll}\mathrm{D}-\mathrm{H} & \mathrm{d}(\mathrm{D}-\mathrm{H}) & \mathrm{d}(\mathrm{H} \cdots \mathrm{A}) & <\mathrm{DHA} & \mathrm{d}(\mathrm{D} \cdots \mathrm{A}) & \mathrm{A} \\ \mathrm{O}(11)-\mathrm{H}(11 \mathrm{C}) & 0.85 & 2.05 & 122.2 & 2.601(15) & \mathrm{O}(9)^{a} \\ \mathrm{O}(10)-\mathrm{H}(10 \mathrm{D}) & 0.85 & 2.49 & 138.4 & 3.17(2) & \mathrm{O}(10)^{a} \\ \mathrm{O}(9)-\mathrm{H}(9 \mathrm{~A}) & 0.85 & 2.01 & 125.4 & 2.601(15) & \mathrm{O}(11)^{a} \\ \mathrm{O}(8)-\mathrm{H}(8 \mathrm{~A}) & 0.85 & 1.48 & 140.7 & 2.201(9) & \mathrm{O}(8)^{a} \\ \mathrm{O}(9)-\mathrm{H}(9 \mathrm{D}) & 0.85 & 2.06 & 177.3 & 2.905(14) & \mathrm{O}(10) \\ \mathrm{O}(8)-\mathrm{H}(8 \mathrm{~B}) & 0.85 & 1.85 & 134.8 & 2.525(11) & \mathrm{O}(9) \\ \mathrm{O}(6)-\mathrm{H}(6 \mathrm{~A}) & 0.95(8) & 2.53(8) & 116(6) & 3.072(6) & \mathrm{O}(4)^{b}\end{array}$

Symmetry codes: ${ }^{a}-\mathrm{x}+1, \mathrm{y},-\mathrm{z}+1 ;{ }^{b} \mathrm{x}, \mathrm{y}+1, \mathrm{z}$. 
Figure S1. TG curve of 1.

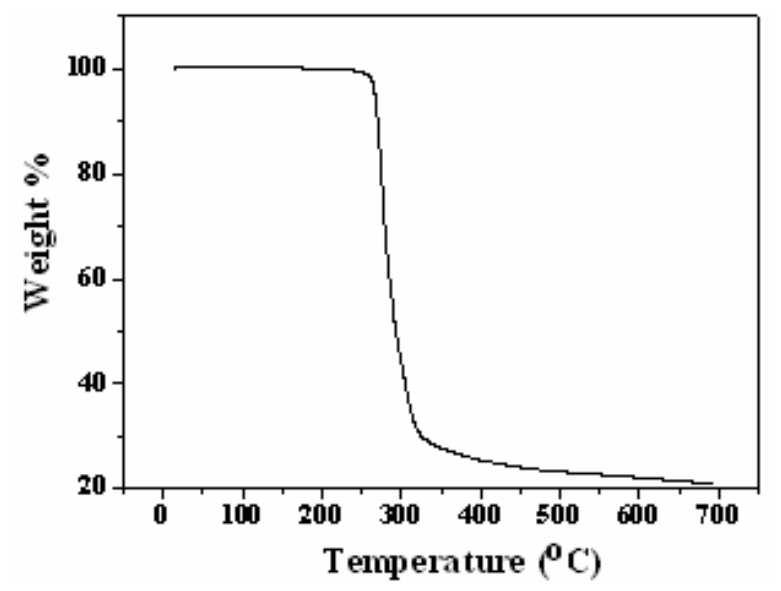

Figure S2. TG curve of 2.

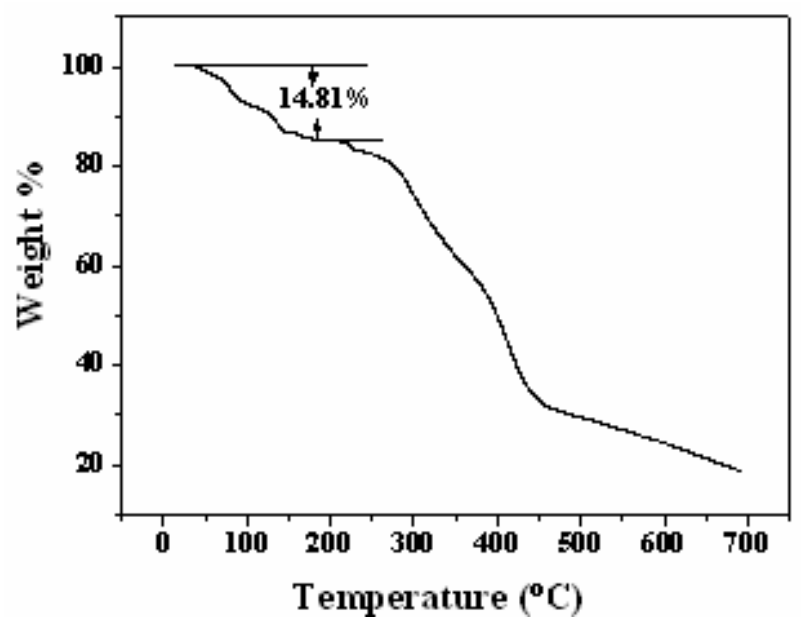

Figure S3. TG curve of 3.

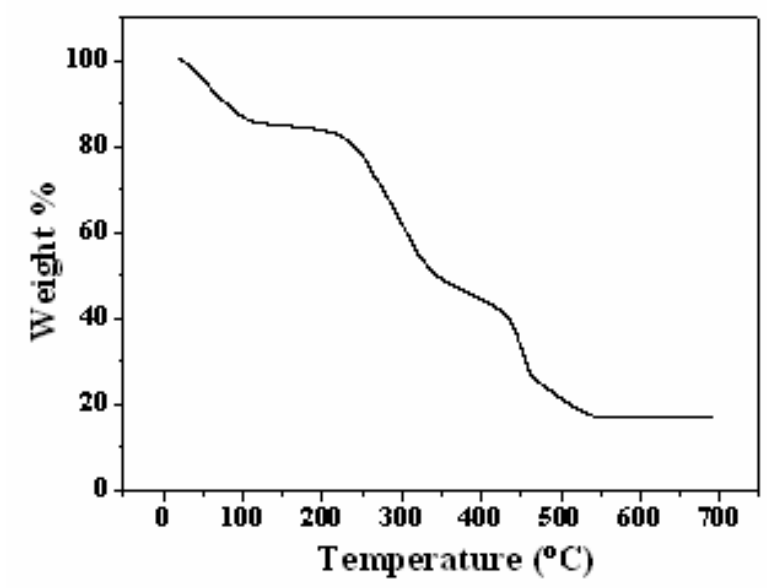


Figure S4. PXRD patterns for 3. Top: taken at room temperature, and down: after heating to $150^{\circ} \mathrm{C}$ for two hours.

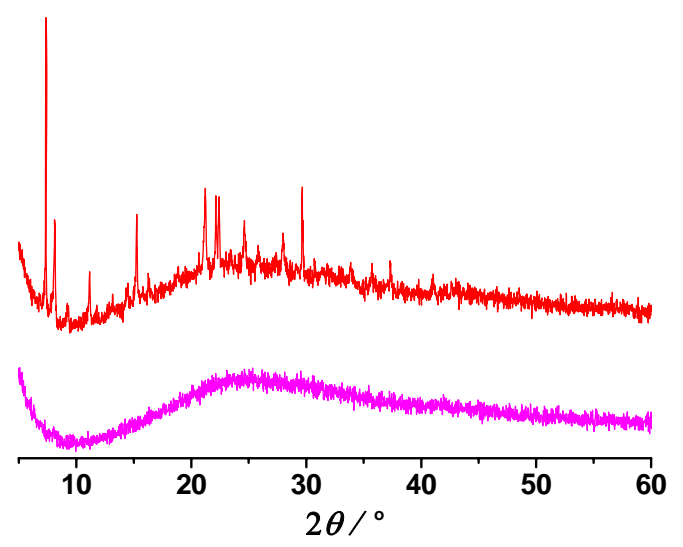

Figure S5. Magnetic behavior of the complex 1 in the form of $\chi_{m} T$ vs $T$ and $\chi^{-1}$ vs $T$ (insert) plots for $\mathbf{1}$. Solid line shows the best fit to the model.

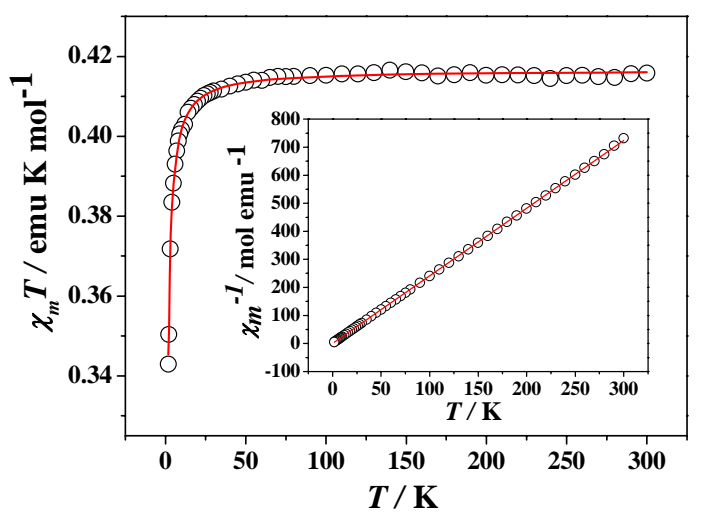

Figure S6. Magnetic behavior of the complex 2 in the form of $\chi_{m} T$ vs $T$ and $\chi^{-1}$ vs $T$ (insert) plots for $\mathbf{2}$. Solid line shows the best fit to the model.

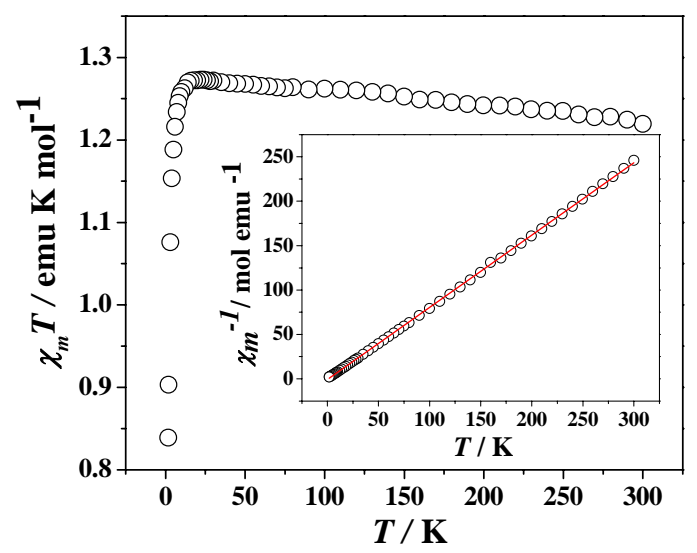


Figure S7. Magnetic behavior of the complex 3 in the form of $\chi_{m} T$ vs $T$ and $\chi^{-1}$ vs $T$ (insert) plots for $\mathbf{3}$. Solid line shows the best fit to the model.

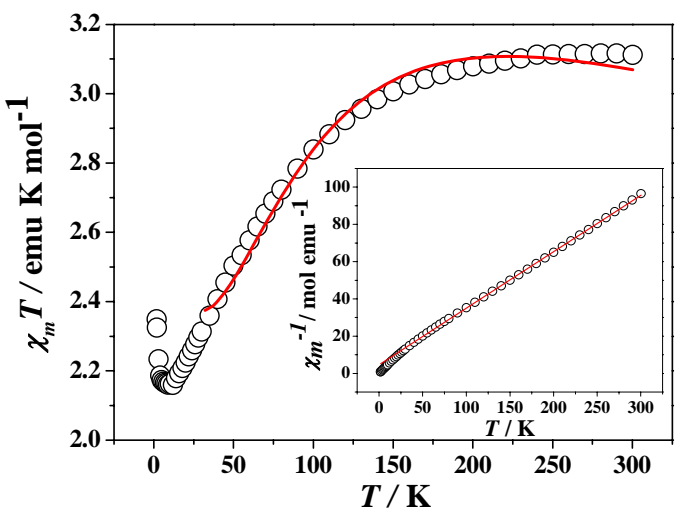

Assuming that all the couplings are very weak (carboxylate in syn-anti conformation and long bpy ligand), ${ }^{1}$ in the case of $\mathbf{3}$, we fitted our experimental data above $30 \mathrm{~K}$ by considersing a mononuclear $\mathrm{Co}^{2+}$ ion with spin-orbit coupling parameter $\lambda(H=-\lambda L S$, $\lambda=-170 \mathrm{~cm}^{-1}$ for the free ion), in a molecular-field approximation, and taken $z J$ as the total exchange parameter. ${ }^{2-7}$

$\chi_{\text {mono }}=\frac{1}{T} \times \frac{\frac{7(3-A)^{2} x}{5}+\frac{12(2+A)^{2}}{25 A}+\left[\frac{2(11-2 A)^{2} x}{45}+\frac{176(2+A)^{2}}{675 A}\right] \exp \left(\frac{-5 A x}{2}\right)+\left[\frac{(5+A)^{2} x}{9}-\frac{20(2+A)^{2}}{27 A}\right] \exp (-4 A x)}{\frac{8 x}{3}\left[3+2 \exp \left(\frac{-5 A x}{2}\right)+\exp (-4 A x)\right]}$ $\chi=\frac{\chi_{\text {mono }}}{1-\left(2 z J / N g^{2} \beta^{2}\right) \chi_{\text {mono }}}$

In two equations, $N, g, \beta, k_{B}$, and $T$ have their usual meanings. The parameter $A$ gives a measure of the crystal field strength relative to the interelection repulsions and is equal to 1.5 for a weak crystal field, 1.32 for a free ion, and 1.0 for a strong field. ${ }^{6}$ The best fit (Figure S7) gives $\lambda=-146 \mathrm{~cm}^{-1}, A=1.20, \mathrm{~g}=2.51$, and $z J=2.32 \mathrm{~cm}^{-1}$ with $\mathrm{R}=8.2 \times 10^{-4}$. The positive $z J$ value indicates the weak ferromagnetic coupling between the $\mathrm{Co}(\mathrm{II})$ ions, which is consistent with the $\chi_{m} T$ value increasing as temperature is lowered from 20 to $2 \mathrm{~K}$. 


\section{References:}

1) Janiak, C. J. Chem. Soc., Dalton Trans. 2003, 2781.

2) Figgis, B. N.; Gerloch, M.; Lewis, J.; Mabbs, F. E.; Webb, G. A. J. Chem. Soc. A 1968, 2086.

3)Mabbs, F. E.; Machin, D. J. Magnetism and Transition Metal Complexes; Chapman and Hall: London, 1973.

4) Kahn, O. Molecular Magnetism; VCH: New York, 1993.

5) Konar, S.; Mukherjee, P. S.; Drew, M. G. B.; Ribas, J.; Chaudhuri, N. R. Inorg. Chem. 2003, 42, 2545.

6) Sun, H.-L.; Wang, Z.-M.; Gao. S. Inorg. Chem. 2005, 44, 2169.

7) Wang, X.-L.; Li, B.-L.; Zhu, X.; Gao, S. Eur. J. Inorg. Chem. 2005, 3277.

6) (a) Casey, A. T.; Mitra, S. Magnetic Behavior of Compounds Containing $d^{n}$ Ions, in Theory and Application of Molecular Paramagnetism; Boudreaux, E. A., Mulay, L. M., Eds.; Wiley-Interscience: New York, 1976. 